\title{
DETERMINING THE MARGINAL WILLINGNESS TO PAY FOR THE CERVICAL CANCER SCREENING PROGRAM IN CROATIA: A BEST-WORST SCALING APPROACH ${ }^{1}$
}

\author{
NIKOLINA DUKIĆ SAMARŽIJA \\ Faculty of Economics, University of Rijeka, Rijeka, Croatia \\ Email: nikolina.dukic.samarzija@efri.hr
}

\begin{abstract}
Croatia is faced with a low response to cancer-screening programs, especially the national cervical cancer screening program, which ultimately resulted in its suspension. If judged solely on the basis of revealed preferences, such a poor response would imply that the population assigns a low social value to preventive screening programs. However, the question arises as to whether revealed preferences (the population's response), in the case of the absence of response to a preventive program, provide insight into its value (utility). Therefore, the objective of this paper is to determine the value that respondents assign to different attributes of cervical screening and, in a broader sense, to decide whether the best-worst scaling (BWS) approach is appropriate for determining the marginal willingness to pay (MWTP) for public health programs. The MWTP for certain attributes of cervical cancer screening is derived from the results of a BWS study conducted in Primorje-Gorski Kotar County, Croatia. The cost function was estimated by regressing the conditional logit coefficients (level of utility) of three levels of the cost attribute on its corresponding values, that is, the hypothetical price. Because the sum of the MWTP corresponds with the market price of a gynecological examination in private practice, we conclude that the results obtained by the BWS confirm the revealed preferences (the market value of the service).
\end{abstract}

Keywords: best-worst scaling, Croatia, preferences, screening, willingness to pay

JEL-codes: D12, I11 


\section{INTRODUCTION}

When a good or service is traded on the market, buyers reveal their preferences directly, through price and quantity signals. In contrast, the value of non-market goods or services, such as health care, is determined administratively and expressed in monetary (willingness to pay [WTP]) or non-monetary terms (quality adjusted life years [QALY]) using an indirect approach through revealed preferences (RP) and a direct approach through stated preferences (SP) (McIntosh 2003). Value is revealed indirectly through a complementary market, for example, the cost of transporting a patient to the screening location, and directly when respondents are asked to assign an economic value to hypothetical goods or services to state their preferences.

When investigating health-related behavior of individuals, health economists use the microeconomic theory of consumers. Individuals maximize their utility, which, among other things, depends on consumption and health conditions. On the one hand, perfect health is a value in itself and a desired goal. On the other hand, there are other goals, whose achievement requires an individual to be in good health. However, individuals do not always behave in the best interest of health preservation - that is, their present behavior reduces the likelihood of health preservation in the future.

If individuals only behaved rationally, the response rate to preventive early disease detection programs would be high. But preventive programs in the Republic of Croatia do not receive this kind of response. Therefore, this poor response (revealed preferences) implies that the population assigns a low social value to preventive public health-care programs. However, the question arises as to whether revealed preferences (the population's response), in the absence of response to preventive programs, provide insight into the value (utility) of the preventive programs. More specifically, it is well known that individuals, even when they consider a certain activity useful, do not necessarily behave accordingly, which can then lead to deviated values based on revealed preferences. Thus, studying individuals' stated preferences is necessary to determine the overall economic value assigned by users of health-care services. With that in mind, the objective of this paper is to determine the value that respondents assign to different attributes of screening programs and, in a broader sense, to decide whether best-worst scaling (BWS) can be used to determine the marginal willingness to pay for public health-care programs.

This research is based on data from empirical research carried out for the National Program of Early Detection of Cervical Cancer in Primorje-Gorski Kotar County (Dukić 2014). The marginal willingness to pay (MWTP) for certain at- 
tributes of screening programs is derived from the result of the conditional logit (Dukić 2014) model and the estimated slope of the budget line.

\section{WELFARE ECONOMICS AND UTILITY EVALUATION IN HEALTH ECONOMICS}

Welfare economics studies alternative economic situations (conditions) from the perspective of social welfare (Koutsoyiannis 1996). It is closely related to the concept of general equilibrium, which was first presented formally by Arrow and Debreu (1954). Market equilibrium is established where market supply and demand are equal. In other words, balance is achieved through individual actions by suppliers and consumers, which is consistent with the theory of the invisible hand formulated by Adam Smith.

The efficient allocation of social resources implies Pareto optimality or efficiency, a situation in which no individual in a society can become better off without making someone else worse off. However, if a certain resource reallocation increases the utility of all individuals in society, it can satisfy the criterion of Pareto improvement. Although, according to a less restrictive version, it is sufficient for only some individuals in society to become better off, without simultaneously making any other individual in society worse off. However, it is impossible to rank reallocation outcomes according to Pareto's improvement criterion if some individuals in the resource reallocation process become better off and others become worse off. These outcomes are considered Pareto inefficient.

In reality, allocations that satisfy Pareto optimality are rare. In most cases, some lose and others gain at the same time, which makes this criteria of little use in decision-making (McGuire 2001). This weakness (Pareto optimum cannot rank all conditions, that is, Pareto improvement is ambiguously defined when some individuals in the society gain and others lose) is also a significant theoretical shortcoming because of its unjustified preference for the status quo. Namely, when all states are compared to the status quo, no change is allowed if someone is placed at a disadvantage, even if this individual's loss is very small, and, at the same time, she/he is one of the richest in society. To overcome the shortcomings of the Pareto criterion, Hicks and Kaldor proposed a compensation criterion that allows potential Pareto improvement (Johansson 1991). In other words, policies, projects, decisions, and so forth satisfy the Hicks-Kaldor compensation criterion if there is a possibility that those who gain from the change compensate for those who lose. Accordingly, John Hicks (1939) introduced equivalent variation (EV) and compensating variation (CV) as measures of consumer welfare. Both vari- 
ations measure in monetary terms the impact on consumer welfare of a change in the price of a good. The CV and EV are very similar concepts, both related to price changes and the impact on the utility level, and they differ according to the prices and utility levels (new or initial) used in their calculation.

$\mathrm{CV}$ is measured by the amount of money that should be given to or received from the consumer in order to return to the initial utility level (before the price change). In other words, in order to calculate a CV, consumer benefit at a new price should be reduced to the initial level by changing the consumer's income level. If the price change makes the consumer worse off, and it is thus necessary to pay that consumer an income supplement to maintain the initial utility level, the $\mathrm{CV}$ can be interpreted as the amount of income that the consumer would be willing to accept (WTA) as compensation for the price change.

In contrast, EV measures how much money the consumer is willing to spend to prevent a price change, which is, essentially, a change in the income level that would bring the consumer to a new utility level, which is equal to the utility level after the price change. In other words, under the influence of income, the consumers' utility level shifts to a new level while the price remains unchanged (old). CV and EV are widespread in economic analysis because they provide a monetary measure of the otherwise abstract utility change. Thus, using the EV or $\mathrm{CV}$ amounts of money, it is possible to determine the extent to which one state is better than another - that is, to measure consumer welfare (Bocksteal McConnell 2007).

In health-care systems, when CV is defined as the willingness to pay (WTP) for an improvement, the equation takes the following form (McGurie 2001):

$$
u_{i}\left(y_{a}-C V, z_{a l}\right)=u_{i}\left(y_{a}, z_{d}\right)
$$

where $u_{i}\left(y_{a^{\prime}} z_{d}\right)$ is the utility of individual $i$ under circumstances described by $a$, while $y_{a}$ is individual income, and $z_{a}$ is the vector of characteristics linked with $a$ that have a certain value for individual $i$. In the case of health, state $a$ may, for example, be poor health or illness, and some of the $z$ characteristics may refer to labor and rest in a condition of illness. CV can be defined as the WTP for improvements in health, given that $a_{l}$ is improvement in it. In other words, $\mathrm{CV}$ represents the maximum amount that can be used to reduce an individual's income without changing the utility level in relation to the initial position before improvement in that person's health. In this case, CV is a positive value deducted from income. However, if an individual becomes worse off after the change (regarding their utility level), the CV should be negative and hence be added to income (two negatives make a positive) for the amount the individual is willing to accept (WTA) as compensation for an aggravated health condition. The sum of individual CVs 
for the transfer from state $a$ to state $a_{1}$ will be positive ( $\left.\Sigma C V>0\right)$ if the monetary value assigned by the winners is greater than the loss of value for the losers.

According to welfare theory, individuals are best at evaluating their own welfare. Under the assumption that the maximum amount an individual is willing to pay (sacrifice) for a certain good or service is an indicator of the utility level for the individual, the monetary value of utility will be determined by individual WTP.

\section{METHODS}

As mentioned in the introduction, we use the results of a BWS study (Dukić 2014) to determine MWTP. This calls for a more detailed description of the method.

\subsection{Best-Worst Scaling}

The best-worst scaling method is a part of broader choice-based methods (MerinoCastelló 2003) that involve everyday activity: choosing between comparable competitive options. In choice-based methods, respondents' preferences are revealed based on their choices (intentions) expressed in certain hypothetical situations. Because individual choices include a certain level of uncertainty (inability to perfectly predict individuals' choices), probabilistic choice (PC) models are used to estimate the likelihood of individual choices. Moreover, this is consistent with random utility theory (Kjær 2005). Therefore, the basic activity of measurements conducted in PC models is a comparison of two or more stimuli, providing information on individual behavior based on a choice (Arons - Krabbe 2013).

In discrete-choice experiments (DCE), respondents are presented with different profiles (scenarios, alternatives) composed of attributes of hypothetical products or services and are asked to make (best) choices. The questionnaire is carefully constructed following the rules of experimental design. Although DCE methodology has made great progress in the evaluation of non-market products and services, especially in the public sector, the DCE format has its limitations, mostly because it provides relatively little information in comparison with other forms (Lancsar et al. 2013). For that reason, Marley and Louviere (2005) developed BWS or the maximum-difference scaling method.

In BWS, respondents are required to choose among different levels of attributes grouped into hypothetical scenarios: one that is the most desirable (best) and one that is the least desirable (worst) (Coltman et al. 2011). Thus, the BWS method uses the inclination of individuals to consistently identify extreme options, which makes it less cognitively demanding for respondents with respect 
to rating and ranking methods. Namely, it became evident that respondents are more inclined to single out the "best" and "worst" items rather than specify the exact order of all offered items. This is certainly an advantage for BWS, making it empirically consistent as opposed to the more complex full-ranking procedure (Coltman et al. 2011).

Furthermore, BWS assumes that an underlying subjective dimension (e.g., the level of importance or preference strength) exists, at which scale a researcher wants to determine the position of the observed item. This is done by simply calculating the absolute and relative choice frequencies. The effectiveness of this method is reflected especially when a larger number of items (attribute levels) are observed (evaluated). An important feature of BWS is that it measures all the attributes with a common scale (Coltman et al. 2011). As a result, BWS circumvents the problem of scale inequality that arises primarily from different styles of responses by individuals (Paulhus 1991) as it is at least as good in predicting as ranking and is bias free (cf. Coltman et al. 2011).

Given that BWS is based on random utility theory, choice frequency is used as a measure of the importance of the observed items (Flynn and Marley 2012). It has been proven (Marley - Louviere 2005) that the difference between the number of choices when a certain level is chosen as best and the number of choices when it is chosen as worst is a close approximation of values obtained by conditional logit analysis. The individual scale for each of the attributes is determined by the number of scenarios offered $(\mathrm{N})$ and does not vary according to the style of the responses, but depends directly on the actual choice of the respondents and can only range from $+\mathrm{N}$ to $-\mathrm{N}$. If, for example, five different scenarios are offered, the scale can only range from +5 to -5 . If a respondent chooses a certain attribute (any of the offered levels) four times as the most important (best) and once as the least important (worst), the result of the best-worst relationship will be +3 .

\subsection{Sample and Estimation}

The methodology used in the study in Primorje-Gorski Kotar County is elaborated elsewhere (Dukić 2014), with the main points in it regarding the reference sample, questionnaire design, and method summarized as follows. A stratified statistical sample was formed based on geographic origin (Rijeka and its surroundings, the coastal area, Gorski Kotar and the islands), and women in the age group 25 to 64 were included in the analysis. Ultimately, $300(N)$ questionnaires were analyzed that meet the criterion of the minimum required sample size (Omre 2006). Attributes (scheduling the examination, waiting for the examination, waiting in the waiting room, waiting for the findings, delivery of the findings, and examination cost) and their levels were selected on the basis of a literature review, interviews 
with gynecologists, coordinators of the screening program, and women who had been invited to the screening. Finally, the selection of the attributes and their levels was confirmed in a pilot study $(N=65)$. The inclusion of the examination cost and its levels (free of charge, HRK 95 [around 50\% of the Croatian Institute for Health Insurance cost], or HRK 188 [100\% of the total cost]) enabled the use of BWS for MWTP estimation as part of this paper's objective. ${ }^{2}$ A paired model conditional logit (Flynn et al. 2008) was used in the econometric assessment of the data. This assumes that respondents consider each scenario separately and choose the most and the least desirable attributes in a scenario: they choose the best-worst pair with the widest distance (maxdiff model; Flynn-Marley 2012). The dependent variable was coded as one for a chosen outcome and as zero for all remaining (non-chosen) pairs in a particular choice set for each individual (see Dukić 2014). As the questionnaire proposed nine different hypothetical scenarios (programs), the respondent had to take into consideration $270(9 \times 30)$ different BW pairs in the entire questionnaire, or 270 observations per questionnaire. This ratio of the information obtained is one of the basic advantages of the BWS over other SP methods.

\subsection{Determining Marginal Willingness to Pay}

In addition to determining the order on the utility scale and identification of attribute levels that give respondents a positive utility level, BWS can be used to estimate marginal willingness to pay for moving from the attributes' lowest utility level to their highest utility level. Marginal willingness to pay for $X_{1}$, that is, the marginal rate of substitution between an attribute and a price, measures the income change that individuals are willing to accept for changing the attribute $X_{1}$, as shown by the following equation (Louviere - Fiebig 2010; McIntosh 2003):

$$
M W T P=\frac{\partial V / \partial X_{1}}{\partial V / \partial p}=\frac{\beta_{1}}{\beta_{P}} .
$$

Assuming that an individual, before and after the change in attribute $X_{1}$, chooses the alternative $j$, the change in the utility level in this case is given by $\Delta_{1} \beta_{1}$, and the $\mathrm{CV}$ measure is given by the following equation (Louviere - Fiebig 2010):

$$
C V=\Delta_{1} \frac{\beta_{1}}{\beta_{p}} \text {. }
$$

According to data from the Croatian National Bank, the exchange rate was around EUR $1=$ HRK 7.64 at the time of the survey. 
If the change represents an improvement, then $\Delta_{1} \beta_{1}>0$ is $\beta_{1}<0$ (i.e., cost line slope), and the resulting $\mathrm{CV}$ is negative, indicating that an individual is willing to accept an income reduction (or cost increase) for the change in attribute $X_{1}$. In other words, on the basis of estimated utility values (econometric model coefficients) of attribute levels and the slope of the cost line, it is possible to calculate the respective WTP in monetary terms for each of the attribute levels of the screening program (Louvere - Islam 2008).

\section{RESULTS}

As elaborated in the previous section, estimated conditional logit coefficients of cost levels (see Appendix 2) and the slope of the cost line are required for the calculation of the MWTP. The cost equation is estimated by regressing (McIntosh 2003) the conditional logit coefficients (level of utility) of three levels of the cost attribute on its corresponding values, i.e., the hypothetical price of screening (Figure 1). Using the slope value (-0.01698) estimated in this manner, it is possible to calculate changes in utility levels due to changes in certain attribute levels, as well as an interdimensional comparison of the observed attributes (Louviere Fiebig 2010; McIntosh 2003). From Figure 1 it is also evident that an increase in the screening cost (shown on the $\mathrm{X}$ axis) leads to a decrease in the level of utility (shown on the $\mathrm{Y}$ axis).

Table 1 presents the MWTP values for a transfer from the lowest utility levels to the highest utility levels for an individual attribute of the screening program, calculated according to Equations (2) and (3).

Table 1. The marginal willingness to pay for attributes of a hypothetical screening program

\begin{tabular}{lll}
\hline Program Attribute & Change in Level & MWTP \\
\hline $\begin{array}{l}\text { Manner of scheduling examination } \\
\text { Waiting period for examination }\end{array}$ & $\begin{array}{l}\text { in person } \rightarrow \text { online } \\
\text { from } 1 \text { to } 3 \text { months } \rightarrow \text { as much } \\
\text { as } 2 \text { weeks } \\
\text { from } 1 \text { to } 2 \text { hours } \rightarrow \text { as much as }\end{array}$ & HRK 82.44 \\
Waiting time in the waiting room & HRK 63.62 \\
Waiting period for findings & $\begin{array}{l}\text { from } 1 \text { to } 3 \text { months } \rightarrow \text { as much as } \\
10 \text { days } \\
\text { mailed to the home address } \rightarrow \text { by } \\
\text { phone }\end{array}$ & HRK 107.75 \\
\hline
\end{tabular}

Source: authors. 


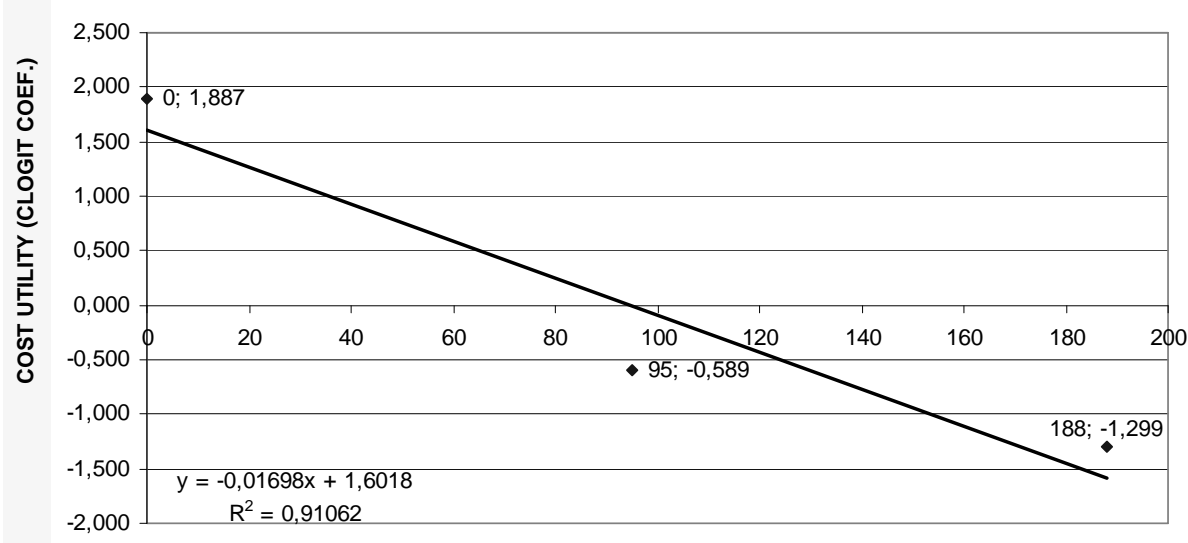

HYPOTHETICAL SCREENING COST IN HRK

Figure 1. Linear Regression of the Screening Cost and its Level of Utility

Source: author.

Except for the fact that it is possible to estimate MWTP for a moving to different levels for a single attribute, it is possible to calculate the change in the utility level (MWTP) that has occurred because of simultaneous changes in the levels of several different attributes. If changes in attribute levels (Table 1) are observed simultaneously, MWTP for moving from a poorly rated program (which implies scheduling an appointment by going to a gynecological clinic in person, a waiting period for the screening from one to three months, waiting in the waiting room for one to two hours, and mailing the findings to the home address) to a better-rated program (scheduling the examination online, waiting for the examination for as much as two weeks, waiting in the waiting room for as much as 30 minutes, waiting for the findings for as much as 10 days, notification about the gynecologist's findings by telephone) can be estimated. It is therefore necessary to calculate the difference in the utility between the two programs and divide the difference obtained by the slope of the cost line.

$$
\begin{gathered}
\text { MWTP }=\quad((0.729+0.691+0.787+0.993+0.605- \\
(-0.671-0.390-0.904-0.836-0.407)) /-0.01698=\text { HRK } 413.01
\end{gathered}
$$

The interpretation of the obtained MWTP values requires caution because it is assumed that the respondent has surely chosen alternative $j$. This can be viewed as a methodological limitation that calls for further study of the application of BWS in evaluating the willingness to pay. Nevertheless, the result obtained can be in- 
terpreted as the amount that women who choose to participate in the screening program are willing to pay for changes in attribute levels of this program.

\section{CONCLUSION}

Setting priorities in health care using an economic approach is not a simple task and is characterized by political and practical difficulties faced by decisionmakers. An economic evaluation can be conducted from different perspectives (society, government, health insurance, health-care facilities), which will then make it difficult to compare different studies. With the exception of evaluation perspectives (e.g., hospitals, third-party payers, patients) the studies also differ according to characteristics of the subjects of analysis (e.g., the national healthcare system, disease, treatment methods), which prevents the generalization of results and conclusions across different circumstances.

Market equilibrium implies a balance between supply and demand; therefore, the estimation of efficiency in the allocation of limited resources is incomplete without analysis of the demand-side factors (Dukić et al. 2015). For this reason, the allocation of health-care resources should be based on the value assigned to them by the consumers of health care (Hurley 2000). Companies in a market create the value of an end product or service by combining production inputs. However, the value expressed by the market price of a product or service is not only influenced by the decisions of suppliers. It is largely determined by preferences of consumers, the actors on the opposite (demand) end of a sales transaction. Namely, a consumer, as a user, is the ultimate judge of the value of a product or a service, which is expressed as their willingness to pay. Having said that, the comparison between different populations' WTP for cervical screening across different countries would be worthless, especially when specific MWTP for moving from a poorly rated screening program to a better-rated screening program is determined, like in this study. On the other hand, the comparison between stated and revealed preferences could serve as a validation of the stated preferences. The amount of HRK 413.01 obtained in this study is similar to the market price of a gynecological examination with the Papanicolaou (Pap) test in private practice. The price for a gynecological examination with the Pap test ranges from HRK 380 to HRK 500, which is evident from an online search of lists of prices for gynecological services in Croatia. Thus, we can conclude that data obtained by the stated preference method (BWS) confirms the revealed preferences (market price of the service), which can also be interpreted as verification of the external validity of the BWS. Moreover, consumer stated preferences should not be ignored in evaluating a product or a service in public health care. 
The importance of demand-side factors is reflected in the evaluation of preferences of health-care service users to gain insights into their motivations and the factors that determine health-related behavior. Stated-preference methods have already proven to lead to similar results as those based on revealed-preference data (Atanasova et al. 2012), and choice-based methods have proven their usefulness in the elicitation of patients' preferences (Baji et al. 2012), which might support sustainable health policy, especially in the new paradigm shift to patientcentered health care (McKee - Nolte 2004; Busse et al. 2010). Also, the increasing emphasis on preventive health policy implies certain sacrifices by individuals with additional costs for material resources (e.g. monthly membership fees for sports activities). Therefore, public health-care programs aimed at promoting good health and illness prevention should be designed according to preferences, i.e. taking into account the motivations of the target population, in order to change unhealthy behavior among individuals who are at risk.

Using the BWS approach makes it possible to calculate the mean utility value for all attribute levels and thus evaluate the impact of each of the observed attributes (unlike the DCE method, in which all scaling values except one are estimated for each of the observed attributes). In addition, impacts of attributes evaluated in this way can be compared, because all attribute levels are estimated on a common scale. Therefore, information on the impact of attributes can be used to create or modify products, programs, or interventions in the public sector, as well as inform policy making (e.g. in health care, community management, and the power industry). Knowledge of MWTP derived from the relative importance of the screening program attributes using BWS is important information for improving the screening program, but it also has larger policy implications, as it provides information on the motivations of the respondents in question.

This paper shows that women who are willing to participate in a screening program are willing to pay larger amounts of money for a reduction in the waiting time for appointments and subsequent findings. This finding is not surprising, given that in the Croatian public health-care system, one gynecologist serves approximately 4,000 patients in primary public health care. Long waits for examination and waiting in the waiting room are well-known shortcomings in health care, and the problem is pronounced in primary as well as secondary health care. The problem is even greater in the case of national preventive health-care programs because their effectiveness (due to poor response by the population) is not at a satisfactory level, which has a negative impact on public expenditure.

On the one hand, decision makers should be familiar with the patients' preferences and their willingness to pay for program improvements, but, on the other hand, patients should possess the skill and ability to understand and process health-related information in order to use health-care services appropriately and 
efficiently. The investigation of the level of health literacy in Primorje-Gorski Kotar County showed that patients' personal characteristics and the accessibility to health-care services influence the level of health literacy (Dukić et al. 2013). This affects the cost of health care as patients who have low health literacy usually do not take the medicaments in the proper manner, which lowers the costeffectiveness of the treatment.

In conclusion, evaluation of populations' preferences (using BWS), especially with respect to the cost of different health interventions, can be very useful in improving the cost effectiveness of preventive activities and public health policies. That said, future research on national screening programs in Croatia should focus on compromises that members of certain homogeneous groups (through an extended sample and econometric model) are willing to make in terms of substituting one program attribute with another.

\section{REFERENCES}

Arons, A. M. - Krabbe, P. F. (2013): Probabilistic Choice Models in Health-State Valuation Research: Background, Theories, Assumptions and Applications. Expert Review Pharmacoeconics and Outcomes Research 13(1): 93-108.

Arrow, K. J. - Debreu, G. (1954): Existence of an Equilibrium for a Competitive Economy. Econometrica 22(3): 265-290.

Atanasova, E. - Pavlova, M. - Moutafova, E. - Kostadinova, T. - Groot, W. (2012): Patient Payments and the Empirical Analysis of Consumer Demand for Hospital Services: An Application for Bulgaria. Society and Economy 34(2): 313-338.

Baji, P. - Pavlova, M. - Gulácsi, L. - Groot, W. (2012): Preferences of Hungarian Consumers for Quality, Access and Price Attributes of Health Care Services - Result of a Discrete Choice Experiment. Society and Economy 34(2): 293-311.

Busse, R. - Blümel, M. - Scheller-Kreinsen, D. - Zentner, A. (2010): Tackling Chronic Disease in Europe: Strategies, Interventions and Challenges. Copenhagen: European Observatory on Health Systems and Policies.

Coltman, T. - Devinney, T. M. - Keating, B. (2011): Best-Worst Scaling Approach to Predict Customer Choice for 3pl Services. Journal of Business Logistics 32(2): 139-152.

Dukić, N. (2014): Vrednovanje izrečenih preferencija u funkciji poboljšanja preventivnih programa javne zdravstvene zaštite [Improvement of the Public Health Care Preventive Programs through Stated Preference Valuation]. PhD Dissertation. Rijeka: University of Rijeka.

Dukić, N. - Blecich Arbula, A. - Cerovic, Lj. (2013): Economic Implications of Insufficient Health Literacy. Economic Research-Ekonomska Istraživanja 26(S1): 117-132.

Dukić, N. - Tomas Žiković, I. - Žiković, S. (2015): Ekonomsko vrednovanje na strani ponude i potražnje - ključ alokacije resursa u javnom zdravstvu [Valuation of Supply and Demand - Key to Public Health Care Resource Allocation]. Ekonomski pregled 66(2): 177-200.

Flynn, T. - Marley, A. J. (2012): Best Worst Scaling: Theory and Methods. Centre for the Study of Choice Working Paper WP12-002. 
Flynn, T. - Louviere, J. J. - Peters, T. J. - Coast J. (2008): Estimating Preferences for a Dermatology Consultation Using Best-Worst Scaling: Comparison of Various Methods of Analysis. BCM Medical Research Methodology 8: 76.

Hicks, J. R. (1939): Value and Capital: An Inquiry into Some Fundamental Principles of Economic Theory. Oxford: Clarendon Press.

Hurley, J. (2000): An Overview of the Normative Economics of the Health Sector. In: Culyer A. J. - Newhouse J. P. (eds): Handbook of Health Economics. Amsterdam: Elsevier Science.

Johansson, P.-O. (1991): An Introduction to Modern Welfare Economics. Cambridge University Press.

Koutsoyiannis, A. (1996): Moderna mikroekonomika [Modern Microeconomics]. Zagreb: Mate.

Lancsar, E. - Louviere, J. J. - Donaldson, C. - Currie, G. - Burgess, L. (2013): Best Worst Discrete Choice Experiments in Health: Methods and an Application. Social Science and Medicine 76: $74-82$.

Louviere, J. J. - Fiebig, D. G. (2010): Benefit Assessment for Cost-Benefit Analysis Studies in Health Care Using Discrete Experiments: Estimating Welfare in a Health Care Setting. In: McIntosh, E. - Clarke, P. M. - Frew, E. J. - Louviere, J. J. (eds): Applied Methods of CostBenefit Analysis in Health Care. Oxford: Oxford University Press.

Louviere, J. J. - Islam, T. (2008): A Comparison of Importance Weights and Willingness-to-Pay Measures Derived from Choice-Based Conjoint, Constant sum Scales and Best-Worst Scaling. Journal of Business Research 61(9): 903-911.

Louviere, J. J. - Woodworth, G. (1983): Design and Analysis of Simulated Consumer Choice or Allocation Experiments: An Approach Based on Aggregate Data. Journal of Marketing Research 20(4): 350-367.

Marley, A. - Louviere, J. J. (2005): Some Probabilistic Models of Best, Worst and Best-Worst Choices. Journal of Mathematical Psychology 49(6): 464-480.

McGuire, A. (2001): Theoretical Concepts in the Economic Evaluation of Health Care. In: Drummond, M. - McGuire, A. (eds): Economic Evaluation in Health Care: Merging Theory with Practice. Oxford: Oxford University Press.

McIntosh, E. S. (2003): Using Discrete Choice Experiments to Value the Benefits of Health Care. $\mathrm{PhD}$ Dissertation. Aberdeen: University of Aberdeen.

Merino-Castello, A. (2003): Eliciting Consumers Preferences Using Stated Preference Discrete Choice Models: Contingent Ranking versus Choice Experiment. UPF Economics and Business Working Paper No. 705.

Paulhus, D. L. (1991): Measurement and Control of Response Bias. In: Robinson J. P. - Shaver P. R. - Wrightsman L. S. (eds): Measures of Personality and Social Psychological Attitude, Measures of Social Psychological Attitudes. San Diego: Academic Press.

Orme, B. K. (2006): Getting Started with Conjoint Analysis: Strategies for Product Design and Pricing Research, Madison, Wisconsin: Research Publishers LLC. 


\section{APPENDIX}

Appendix Table 1. Example of the Profile Case BWS Hypothetical Scenario

\begin{tabular}{l|c|c}
\hline Worst attribute & Programme & Best attribute \\
\hline & You make an appointment by telephone & \\
\hline & You wait for the examination from 1 to 3 months & \\
\hline & You wait for the examination in the waiting room & \\
from 1 to 2 hours & \\
\hline & You wait for the findings from 10 days to 1 month & \\
\hline & You learn about the findings by telephone & \\
\hline & You pay for the examination HRK 95 & \\
\hline
\end{tabular}

Source: Dukić (2014).

Appendix Table 2. Results of the Conditional Logit Model Presented on Underlying Utility Scale

\begin{tabular}{l|c|c|c|c|c|c}
\hline & B & \multicolumn{1}{|c|}{ SE } & \multicolumn{1}{c|}{ Wald } & df & Sig. & Exp(B) \\
\hline Attribute impact & & & & & & \\
\hline Manner of scheduling examination - A1 & 0.606 & 0.049 & 155.855 & 1 & 0.000 & 1.833 \\
\hline Waiting period for examination - A2 & 0.043 & 0.048 & 0.816 & 1 & 0.366 & 1.044 \\
\hline Waiting time in the waiting room - A3 & 0.399 & 0.048 & 67.769 & 1 & 0.000 & 1.490 \\
\hline Period of waiting for findings - A4 & 0.225 & 0.048 & 21.909 & 1 & 0.000 & 1.253 \\
\hline Manner of delivery of findings - A5 & 0.596 & 0.049 & 150.623 & 1 & 0.000 & 1.814 \\
\hline Screening cost - A6 & - & - & - & - & - & - \\
\hline SCALE VALUE & & & & & & \\
\hline A1-1 by phone & -0.058 & - & - & - & - & - \\
\hline A1-2 in person & -0.671 & 0.068 & 97.735 & 1 & 0.000 & 0.511 \\
\hline A1-3 on-line & 0.729 & 0.068 & 115.941 & 1 & 0.000 & 2.073 \\
\hline A2-1 up to 2 weeks & 0.691 & 0.071 & 93.380 & 1 & 0.000 & 1.995 \\
\hline A2-2 from 2 weeks to 1 month & -0.301 & 0.073 & 16.835 & 1 & 0.000 & 0.740 \\
\hline A2-3 from 1 to 3 months & -0.390 & - & & - & - & - \\
\hline A3-1 up to 30 min & 0.787 & 0.068 & 133.016 & 1 & 0.000 & 2.197 \\
\hline A3-2 from 30 min to 1 hour & 0.116 & 0.072 & 2.590 & 1 & 0.108 & 1.123 \\
\hline A3-3 from 1 to 2 hours & -0.904 & - & & - & - & - \\
\hline A4-1 up to 10 days & 0.993 & 0.066 & 227.017 & 1 & 0.000 & 2.700 \\
\hline A4-2 from 10 days to 1 month & -0.157 & 0.071 & 4.872 & 1 & 0.027 & 0.854 \\
\hline A4-3 from 1 to 3 months & -0.836 & - & - & - & - & - \\
\hline A5-1 to the home address & -0.407 & - & - & - & - & - \\
\hline A5-2 by phone & 0.605 & 0.070 & 75.360 & 1 & 0.000 & 1.831 \\
\hline A5-3 personal arrival & -0.198 & 0.070 & 7.880 & 1 & 0.005 & 0.821 \\
\hline A6-1 free & 1.887 & - & - & - & - & - \\
\hline A6-2 95 HRK & -0.589 & 0.068 & 75.577 & 1 & 0.000 & 0.555 \\
\hline A6-3 188 HRK & -1.299 & 0.056 & 528.533 & 1 & 0.000 & 0.273 \\
\hline S & & & & & & \\
\hline
\end{tabular}

Source: Dukić (2014). 
Open Access. This is an open-access article distributed under the terms of the Creative Commons Attribution-NonCommercial 4.0 International License (https://creativecommons. org/licenses/by-nc/4.0/), which permits unrestricted use, distribution, and reproduction in any medium for non-commercial purposes, provided the original author and source are credited, a link to the CC License is provided, and changes - if any - are indicated. 